\title{
Article \\ S and P Dual-Doped Carbon Nanospheres as Anode Material for High Rate Performance Sodium-Ion Batteries
}

\author{
Hyeon-Su Yang ${ }^{1,2}{ }^{\oplus}$, Si-Wan Kim ${ }^{1,2}$, Kwang-Ho Kim ${ }^{3,4}$, Sung-Hwan Yoon ${ }^{2,5}$, Min-Jae Ha ${ }^{6}$ and Jun Kang ${ }^{2,5, * \mathbb{C}}$ \\ 1 Department of Marine Engineering, Korea Maritime \& Ocean University, Yeongdo-gu, Busan 49112, Korea; \\ wjsfo5648@g.kmou.ac.kr (H.-S.Y.); wandumpling@g.kmou.ac.kr (S.-W.K.) \\ 2 Interdisciplinary Major of Maritime AI Convergence, Korea Maritime \& Ocean University, Yeongdo-gu, \\ Busan 49112, Korea; shy@kmou.ac.kr \\ 3 School of Materials Science and Engineering, Pusan National University, 63 beon-gil, Geumjeong-gu, \\ Busan 46241, Korea; kwhokim@pusan.ac.kr \\ 4 Global Frontier R\&D Center for Hybrid Interface Materials, Pusan National University, 63 beon-gil, \\ Geumjeong-gu, Busan 46241, Korea \\ 5 Department of Marine System Engineering, Korea Maritime \& Ocean University, Yeongdo-gu, \\ Busan 49112, Korea \\ 6 Department of Coast Guard Studies, Korea Maritime \& Ocean University, Yeongdo-gu, Busan 49112, Korea; \\ hmj153@kmou.ac.kr \\ * Correspondence: junkang@kmou.ac.kr; Tel.: +82-051-410-4281
}

Citation: Yang, H.-S.; Kim, S.-W.; Kim, K.-H.; Yoon, S.-H.; Ha, M.-J.; Kang, J. S and P Dual-Doped Carbon Nanospheres as Anode Material for High Rate Performance Sodium-Ion Batteries. Appl. Sci. 2021, 11, 12007. https://doi.org/10.3390/ app112412007

Academic Editor: Roberto Gunnella

Received: 18 November 2021 Accepted: 11 December 2021 Published: 16 December 202

Publisher's Note: MDPI stays neutral with regard to jurisdictional claims in published maps and institutional affiliations.

Copyright: () 2021 by the authors. Licensee MDPI, Basel, Switzerland. This article is an open access article distributed under the terms and conditions of the Creative Commons Attribution (CC BY) license (https:// creativecommons.org/licenses/by/ $4.0 /)$.

\begin{abstract}
The heteroatom doping of carbon materials can significantly improve the electrochemical performance of sodium-ion batteries. However, conventional doping techniques involve more than two steps, making them unsuitable for scale-up. In this study, an S and P co-doped carbon material is synthesized using a simple, one-step plasma-in-liquid process. The synthesized material consists of abundant macropores, which can improve the electrochemical properties of sodium-ion batteries. When the synthesized anode material is applied to a sodium-ion half-cell, the cell exhibits a remarkable cycling life of 3000 cycles at a high current density of $10 \mathrm{~A} \mathrm{~g}^{-1}$, with a high reversible capacity over $125 \mathrm{mAh} \mathrm{g}^{-1}$. These results indicate that $\mathrm{S}$ and $\mathrm{P}$ co-doped carbon materials are promising candidates as anodes for sodium-ion batteries, and the plasma-in-liquid process is an effective strategy for heteroatom co-doping.
\end{abstract}

Keywords: sodium-ion batteries; plasma-in-liquid process; heteroatom doping; anode material

\section{Introduction}

Lithium-ion batteries (LIBs) are used for energy storage in various electronic devices, owing to their high energy density and excellent cycling stability [1-3]. However, the increasing demand for electric vehicles has increased the consumption of lithium [4,5]. Moreover, only a few lithium reserves are available for mining, and the cost of lithium is increasing because of its uneven distribution around the world. These drawbacks limit the applications of LIBs in future electric devices [6,7].

Sodium-ion batteries (SIBs) are considered to be the future energy storage devices because they are inexpensive and their operation is similar to that of LIBs [8]. However, the electrochemical performance of SIBs is insufficient, owing to their low first-cycle Coulombic efficiency and the limitations of the carbon material $[9,10]$. This insufficient electrochemical performance is due to the fact that the ionic radius of sodium is larger than that of lithium, which decreases the diffusion rate to the electrode material. Moreover, sodium is thermodynamically unstable when forming compounds with graphite, which results in its negligible insertion into the graphene layer [11,12]. Thus, the reversible capacity of a sodium-ion cell is determined by the adsorption onto the graphite surface, with ions stored in the void space in the disordered region, rather than being inserted. 
Therefore, the development of suitable electrode materials that offer high energy density, reversibility, and rapid ion insertion/extraction is essential.

In this study, we aim to improve the electrochemical performance of carbon materials by co-doping heteroatoms, such as $\mathrm{S}$ and $\mathrm{P}$, within the carbon matrix. S-doping increases the reversible capacity by widening the distance between the carbon layers, and causes a reversible reaction with sodium ions [13-15]. P-doping improves the electrochemical performance by inducing defects on the material surface and forming abundant active sites [16,17]. In addition, a simple plasma-in-liquid process is used for doping the heteroatoms, rather than complex processes. The $\mathrm{S}$ and $\mathrm{P}$ co-doped carbon material (SP/C) exhibits high initial Coulombic efficiency and excellent reversible capacity with a long cycling life, even though SP/C is a nanomaterial with a large specific surface area.

\section{Materials and Methods}

\subsection{Material Synthesis}

$\mathrm{S}$ and $\mathrm{P}$ co-doped carbon materials were synthesized using the plasma-in-liquid process. A schematic of the synthesis is shown in Figure 1. A solution, which consisted of melted triphenylphosphine and thiophene in a 1:1 ratio, was used as a precursor for synthesizing the anode material. A pair of tungsten electrodes (Nilaco, Japan) was installed, and the electrodes faced each other at an interval of approximately $1 \mathrm{~mm}$. A pulse voltage was applied using a high-voltage bipolar pulse generator (PeKuris, MPP-HV04), and the voltage, frequency, and pulse width were set to $2.0 \mathrm{kV}, 100 \mathrm{kHz}$, and $1.0 \mu \mathrm{s}$, respectively. The synthesized anode material was filtered through a membrane filter and dried in an oven at $90{ }^{\circ} \mathrm{C}$ for $12 \mathrm{~h}$. After the dried material was ground using a mortar, it was heattreated at $500{ }^{\circ} \mathrm{C}$ for $1 \mathrm{~h}$ in a nitrogen atmosphere using an electric furnace to improve the electrical conductivity.

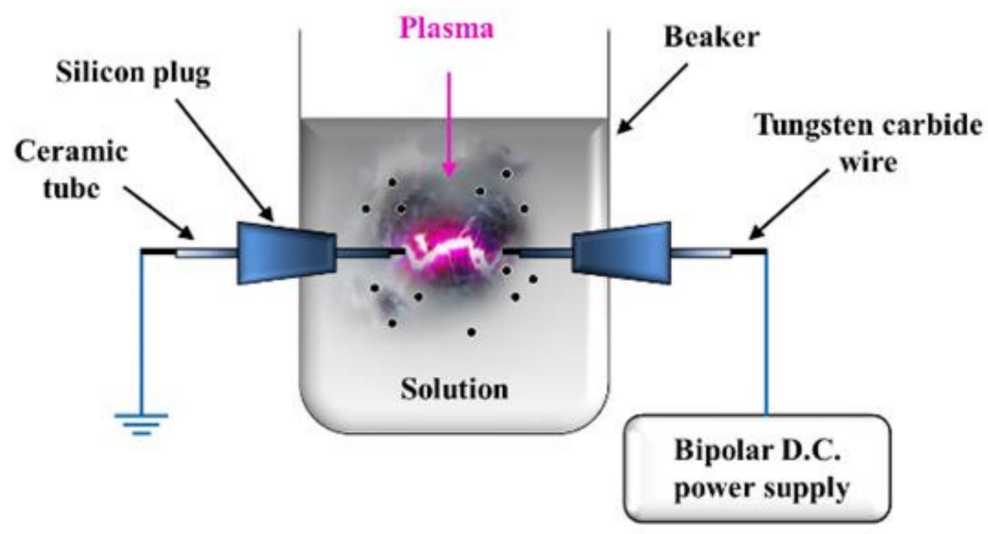

Figure 1. Schematic illustration of the experimental set up for plasma-in-liquid process.

\subsection{Material Characterization}

The morphologies of the sample surfaces were observed using transmission electron microscopy (TEM, JEM-2100F), high-resolution TEM (HR-TEM, JEM-2100F) and scanning electron microscopy (SEM, MIRA3, Tescan). Elemental mapping was performed using energy-dispersive $\mathrm{X}$-ray spectroscopy (EDS) attached to the TEM. The structural characteristics were determined by $\mathrm{X}$-ray diffractometer (XRD) using filtered $\mathrm{Cu} \alpha$ radiation (SmartLab, RIGAKU). $\mathrm{N}_{2}$ adsorption-desorption isotherms were obtained at $77 \mathrm{~K}$ using a $\mathrm{N}_{2}$ adsorption analyzer (MicrotracBEL Corp., BELSORP-max). Specific surface areas were evaluated using the Brunauer-Emmett-Teller (BET) method. Pore sizes were determined using the Barrett-Joyner-Halenda (BJH) method and micropore analysis (MP). 


\subsection{Electrochemical Measurements}

The synthesized anode material was mixed with conductive carbon black (TIMCAL Graphite and Carbon Super P) and carboxymethyl cellulose binder in a mass ratio of 7:1:2, and distilled water was added to prepare a slurry. The slurry was mixed using a conditioning mixer (THINKY Corp., Chiyoda-ku, Japan). The mixed slurry was uniformly coated onto copper foil with a thickness of $35 \mu \mathrm{m}$ using a mini coater (MC-30, HOSEN Corp., Osaka, Japan), and the solvent was removed by drying in an oven at $80{ }^{\circ} \mathrm{C}$ for $12 \mathrm{~h}$. The dried sample was pressed using a roll press, and then punched into a circular shape with $14 \mathrm{~mm}$ diameter. The mass loading of the active material in the produced electrode was $0.4-0.5 \mathrm{mg} \mathrm{cm}^{-2}$.

The prepared electrode was used in a CR2030-type coin cell (Wellcos Corp., Gunpo, Gyeonggi-do, Korea). Sodium was used as the counter electrode, and all assembly processes were performed in a glove box filled with argon gas. Glass fiber was used as the separator, and diethylene glycol dimethyl ether, in which $1 \mathrm{M} \mathrm{NaPF}_{6}$ was dissolved, was used as the electrolyte. Galvanostatic discharge/charge and cyclic voltammetry $(\mathrm{CV})$ tests were performed in the voltage range of $0.01-3.0 \mathrm{~V}\left(\mathrm{vs} . \mathrm{Na}^{+} / \mathrm{Na}\right.$ ) using BCS-805 Biologic battery test system.

\section{Results and Discussion}

The morphology of the synthesized SP/C was analyzed using TEM and HR-TEM. From the TEM image (Figure 2a), it was confirmed that the particles of SP/C were ballshaped, similar to carbon black, and were connected to each other. The SEM image is also shown in Figure S1. This structure revealed that SP/C had channels, through which Na ions could easily move between particles. Previous studies revealed that this structure facilitated fast electrochemical reactions, resulting in efficient $\mathrm{Na}$ ion exchange, even at large current densities $[18,19]$. In addition, the EDS results confirmed that $C, S$, and $P$ were evenly distributed in the synthesized material. The elemental composition of SP/C was C, S, and $\mathrm{P}$ at 75.1, 18.6, and 6.3 wt.\%, respectively, according to the EDS results.
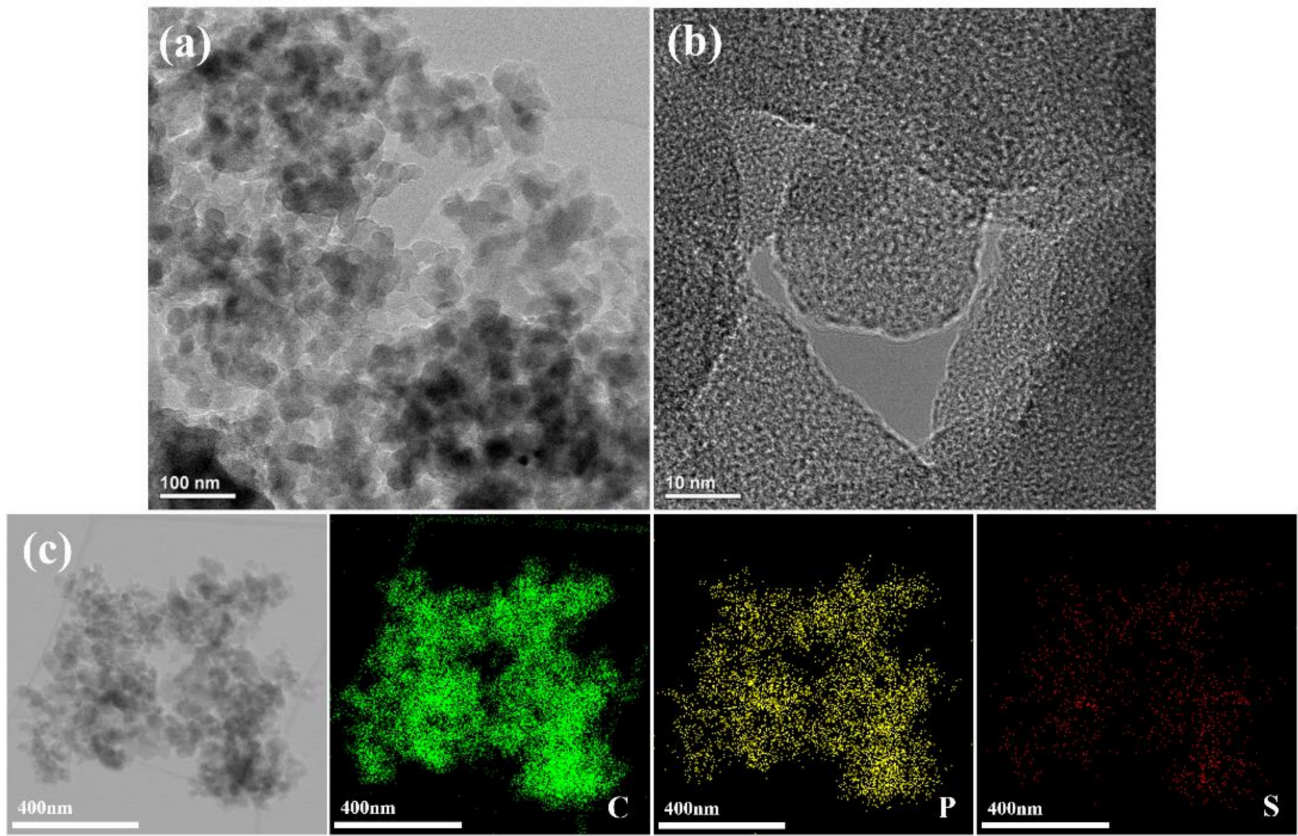

Figure 2. Morphology of SP/C (a) TEM image, (b) HR-TEM image and (c) EDS mapping.

Figure 3a shows the XRD pattern of SP/C. The peaks observed in the (002) and (100) planes represent typical graphite peaks. These peaks are widespread, indicating that SP/C has an amorphous structure. To investigate the changes in the XRD pattern caused by $S$ and $\mathrm{P}$ doping, an XRD pattern of an undoped carbon material synthesized by the same 
synthesis method, using a xylene precursor, was obtained (Figure S2). However, the SP/C and undoped carbon are both amorphous carbon structures; therefore, there is no noticeable peak resulting from heteroatom doping. The d-spacing value of SP/C was calculated to be $\sim 0.40 \mathrm{~nm}$ using Bragg's equation. Furthermore, based on the Scherrer equation, the c-axis length was calculated to be $1.58 \mathrm{~nm}$, indicating that the number of stacked graphitic sheets was approximately four layers. This nanocrystalline carbon structure can improve specific surface areas with sufficient pore volumes to facilitate rapid $\mathrm{Na}$ ion exchange [20].
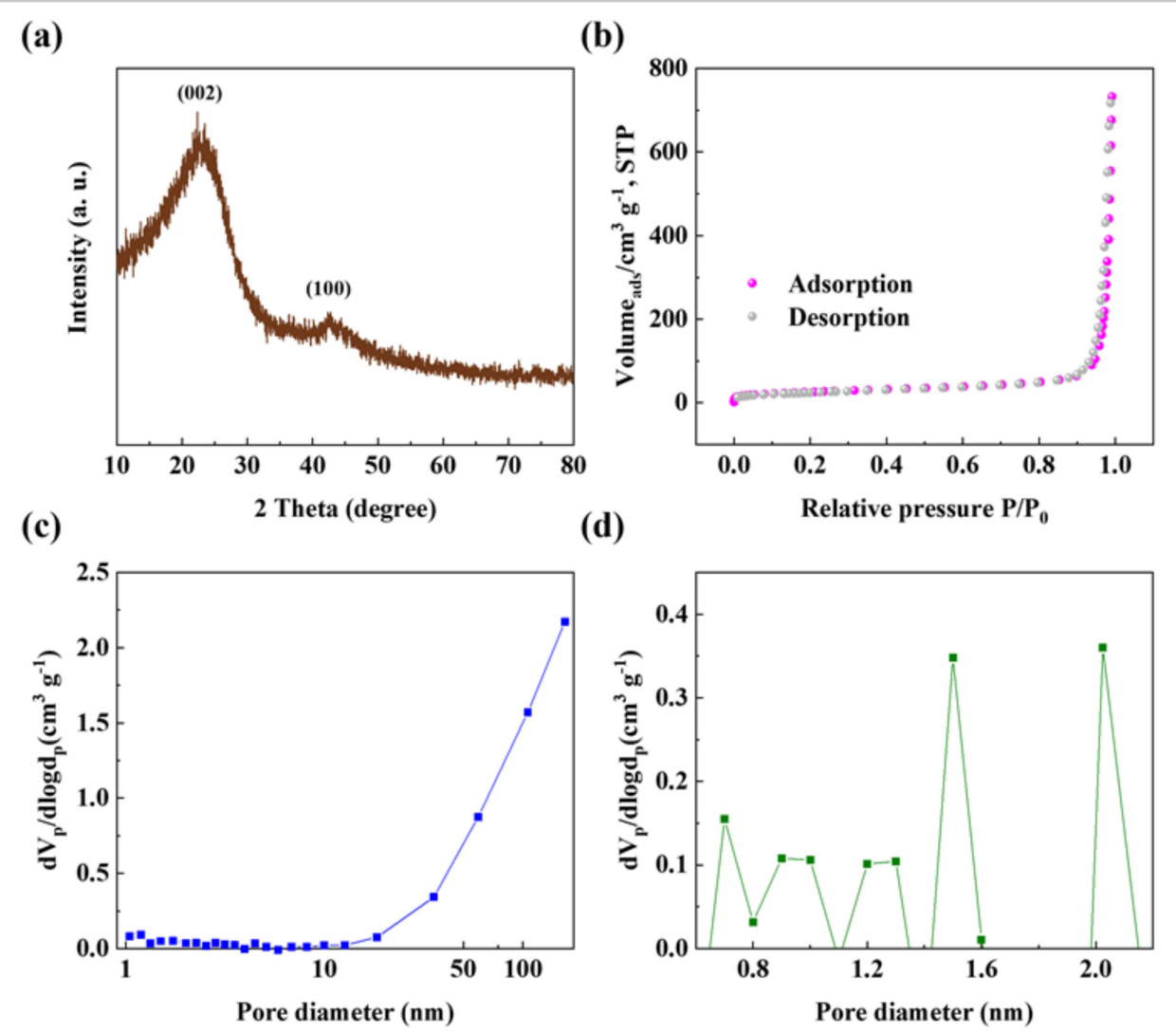

Figure 3. (a) XRD patterns of $\mathrm{SP} / \mathrm{C}$; (b) $\mathrm{N}_{2}$ adsorption-desorption isotherm; (c) $\mathrm{BJH}$ pore size distribution; (d) micropore size distribution.

In addition, the pore structure of SP/C was analyzed using the $\mathrm{N}_{2}$ adsorptiondesorption isotherms (Figure 3b). The specific part of SP/C was measured at $92.06 \mathrm{~m}^{2} \mathrm{~g}^{-1}$ using the BET measurements, and this large specific surface area indicated that the contact surface between the electrode and electrolyte interface is wide, thereby facilitating $\mathrm{Na}$ ion exchange. The data related to the BET plot and the fitted line used to calculate the specific surface area are shown in Figure S3 and Table S1. The pore size distributions measured by the BJH and MP methods are shown in Figure 3c,d, respectively. The pore size was distributed over $12 \mathrm{~nm}$, which indicated the abundant formation of macropores. However, micropores hardly existed. These large and small pores facilitated fast sodium ion exchange, and the large specific surface area significantly increased the storage volume by the adsorption of sodium ions. Furthermore, the macropore and total pore volume was $1.0317 \mathrm{~cm}^{3} \mathrm{~g}^{-1}$, and the average pore diameter was $33.046 \mathrm{~nm}$.

Figure 4a shows the first-cycle charge/discharge profile at a current density of $1 \mathrm{~A} \mathrm{~g}^{-1}$. Although it was a nanomaterial, SP/C exhibited a high first-cycle Coulombic efficiency of approximately $84.6 \%$, owing to the use of the plasma-in-liquid process. Previous studies confirmed that a solid electrolyte interface (SEI) layer is not formed in an ether-based electrolyte $[21,22]$. Therefore, the absence of an SEI layer may affect the high initial Coulombic 
efficiency. The oxidation/reduction of SP/C, in the potential window, was investigated using the CV curve, as shown in Figure $4 \mathrm{~b}$. In the first cycle, a cathodic peak was observed at approximately $1.2 \mathrm{~V}$. This could be attributed to the Na ions trapped inside the carbon material in the anode. When the $\mathrm{Na}$ ions intercalated into the carbon material, the occurrence of local and large expansion inside the structure trapped some $\mathrm{Na}$ ions in the intercalated position [23]. After the first cycle, there was no significant change.

(a)

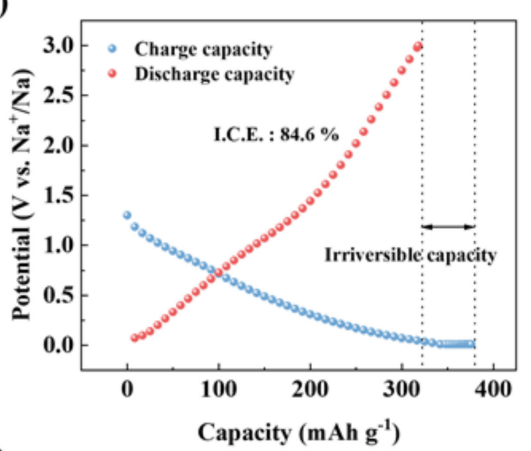

(c)

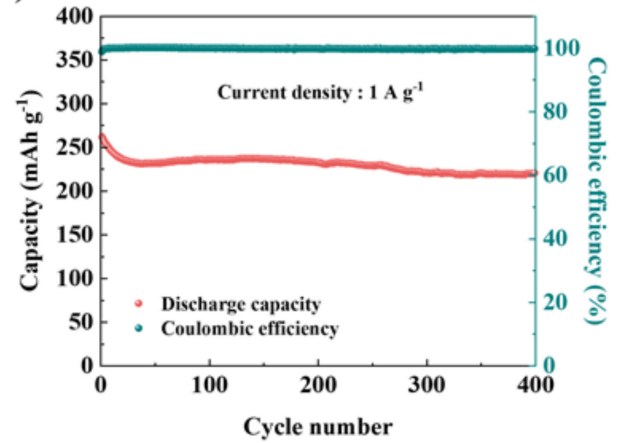

(b)

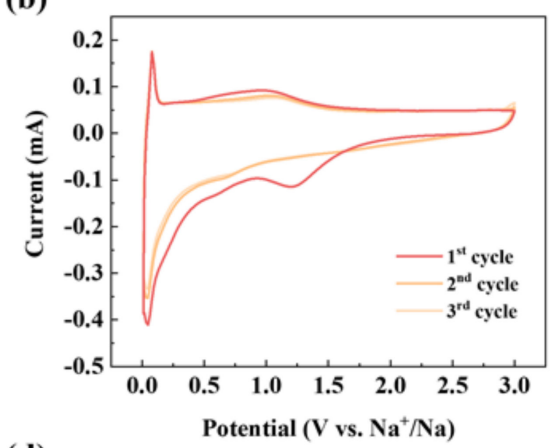

(d)

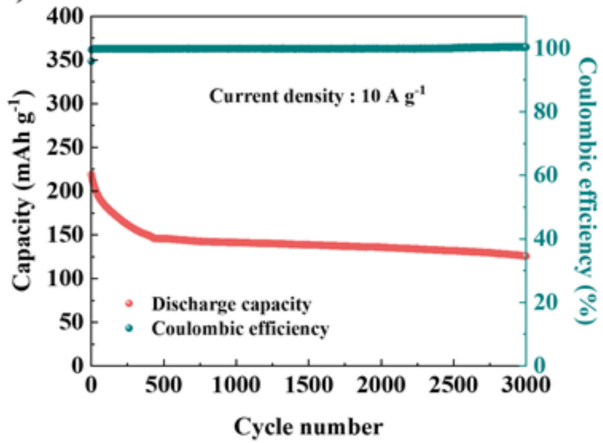

Figure 4. (a) Charge/discharge curves of SP/C during the first cycle; (b) CV curves of SP/C at a scan rate of $0.2 \mathrm{mV} \mathrm{s}^{-1}$; (c) cycling performance of SP/C in SIB at current densities of $1 \mathrm{~A} \mathrm{~g}^{-1}$ and (d) $10 \mathrm{~A} \mathrm{~g}^{-1}$.

The cycling performance of SP/C was obtained by charging/discharging at various current densities. Figure $4 \mathrm{c}$ shows the charge/discharge profile at a current density of $1 \mathrm{~A} \mathrm{~g}^{-1}$. SP/C exhibited a reversible capacity of approximately $220 \mathrm{mAh} \mathrm{g}^{-1}$ or higher. Initially, a reversible capacity of approximately $260 \mathrm{mAh} \mathrm{g}^{-1}$ was observed. However, the discharge capacity decreased with an increasing number of cycles, and it was stable from the $\sim 30$ th cycle. The charge/discharge profile at a higher current density of $10 \mathrm{Ag}^{-1}$ is shown in Figure 4d. Starting with a discharge capacity of approximately $220 \mathrm{mAh} \mathrm{g}^{-1}$, it decreased to approximately $125 \mathrm{mAh} \mathrm{g}^{-1}$ at the 3000th cycle. However, it exhibited an excellent cycling life.

A rate capability test was performed to determine the stability of SP/C (Figure 5a). The current density was increased from 1 to $100 \mathrm{~A} \mathrm{~g}^{-1}$, and further decreased to $1 \mathrm{~A} \mathrm{~g}^{-1}$. Discharge capacities of approximately $271,242,211,189,170,157,146,138,132,125,120$, 116, and $112 \mathrm{mAh} \mathrm{g}^{-1}$ were observed at the current densities of 1, 2, 5, 10, 20, 30, 50, 50, $60,60,70,80,80,90$, and $100 \mathrm{~A} \mathrm{~g}^{-1}$, respectively. The stability was confirmed by almost recovering the original reversible capacity at $1 \mathrm{~A} \mathrm{~g}^{-1}$. The excellent rate performance of $\mathrm{SP} / \mathrm{C}$ could be attributed to the presence of numerous macropores, owing to the co-doping of $S$ and $P$ [24]. This could be further explained by the charge/discharge profiles at each current density (Figure 5b). As the current density increased, the flat section sharply decreased, indicating that the adsorption of Na ions at the active site was much faster than the intercalation between the graphene layers. In other words, the macropores narrowed 
the diffusion distance of $\mathrm{Na}$ ions and increased the diffusion rate. The abundant active sites increased the Na storage capacity by the adsorption of numerous $\mathrm{Na}$ ions.

(a)

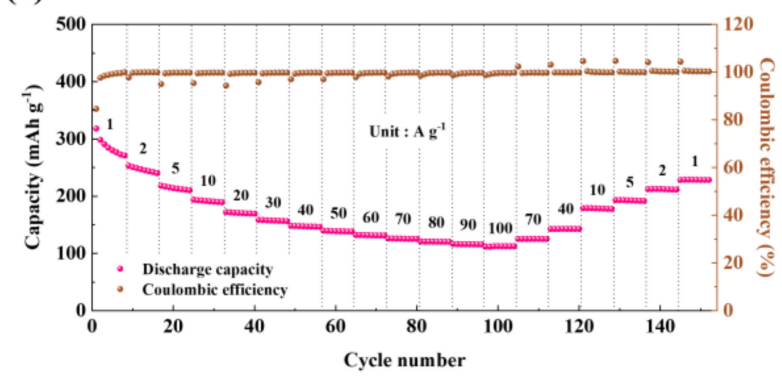

(b)

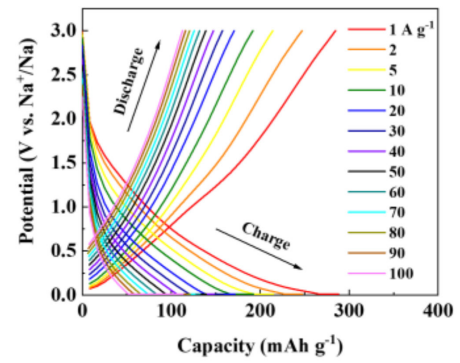

Figure 5. (a) Rate capability at various current densities ranging from 1 to $100 \mathrm{~A} \mathrm{~g}^{-1}$; (b) charge/discharge profiles at different rates.

To further analyze the excellent rate performance of SP/C, CV was conducted at various scan rates, from $0.2 \mathrm{mV} \mathrm{s}^{-1}$ to $2.0 \mathrm{mV} \mathrm{s}^{-1}$, for investigating the reaction kinetics (Figure 6a). As the scan rate increased, the peak current also increased, but the shape of the $\mathrm{CV}$ curve remained similar. Therefore, the capacitive behavior was analyzed for the scan rate and peak current, as shown in Equation (1) [25,26].

$$
i(V)=a v^{b},
$$

where $a$ and $b$ are the correlation coefficients, $v$ is the scan rate, and $i$ is the current. When $a$ value $b$ approaches 0.5 , it indicates a diffusion-controlled process; whereas, when $a$ value $b$ approaches 1.0, it indicates a surface-controlled process. Figure $6 \mathrm{~b}$ represents the slope corresponding to Equation (1) at $0.1 \mathrm{~V}$, and the $b$ values of the cathodic and anodic peak in this potential are 0.9038 and 0.9010 , respectively. Both values are close to 1.0, indicating that the kinetics mainly correspond to the surface-controlled process.

(a)

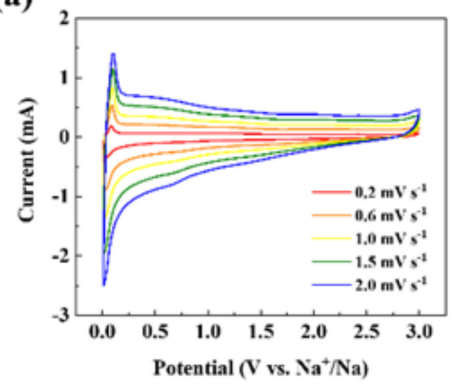

(c)

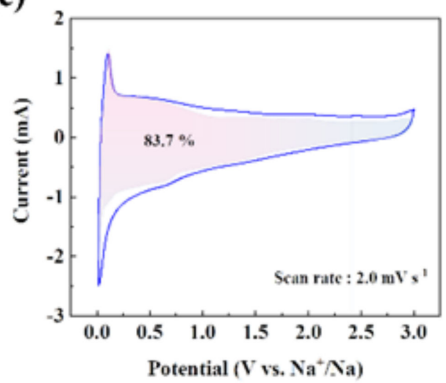

(b)

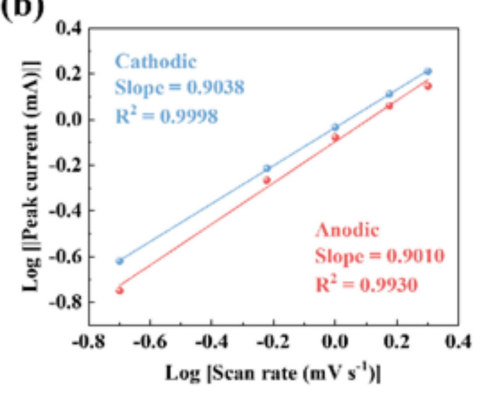

(d)

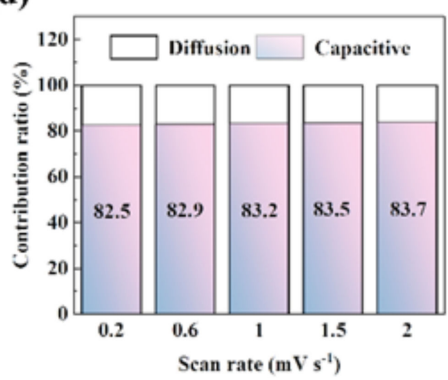

Figure 6. (a) $\mathrm{CV}$ curves of $\mathrm{SP} / \mathrm{C}$ at various scan rates from 0.2 to $2.0 \mathrm{mV} \mathrm{s}^{-1}$; (b) linear relationship between the logarithms of the current and scan rates of the cathodic and anodic peaks at $0.1 \mathrm{~V}$; (c) CV curve and capacitive contribution of SP/C at a scan rate of $2.0 \mathrm{mV} \mathrm{s}^{-1}$; (d) corresponding capacitive contribution to the total capacity at different scan rates. 
The relative contributions of the intercalation and capacitive processes at a specific scan rate can be calculated using Equation (2) $[27,28]$.

$$
i(V)=k_{1} v+k_{2} v^{1 / 2},
$$

where $k_{1} v$ and $k_{2} v^{1 / 2}$ represent the contributions of the intercalation or capacitive processes, respectively. Figure $6 \mathrm{c}$ shows the contribution of the capacitive process at a scan rate of $2.0 \mathrm{mV} \mathrm{s}^{-1}$ of SP/C, which is approximately $83.7 \%$. The capacitive process contributions at other scan rates, measured by the same method, are also shown in Figure $6 \mathrm{~d}$, and exhibited more than $82 \%$ in all the scan rates. These results show that, in the sodium-ion exchange process of $\mathrm{SP} / \mathrm{C}$, a fast capacitive process is dominant in most of the capacity, which is the basis for a high rate performance.

\section{Conclusions}

In summary, $\mathrm{S}$ and $\mathrm{P}$ co-doped carbon materials were synthesized using a simple plasma-in-liquid process. The $\mathrm{S}$ and $\mathrm{P}$ doping levels of the synthesized material were 18.6 and $6.3 \mathrm{wt} . \%$, respectively, and it was confirmed that they were evenly distributed in the material. When SP/C was applied as an anode in SIBs, SP/C exhibited excellent rate capability and cycling life. At a high current density of $10 \mathrm{~A} \mathrm{~g}^{-1}, \mathrm{SP} / \mathrm{C}$ exhibited a reversible capacity of $125 \mathrm{mAh} \mathrm{g}^{-1}$, even after 3000 cycles. In addition, the rate capability test confirmed that SP/C exhibited excellent reversible capacity, even at a high current density, and the stability was immediately recovered at a low current density. Moreover, most of the Na storage mechanisms of SP/C were due to the adsorption on the surface. It is considered that better results can be obtained if the S-to-P ratio is further adjusted through research. In addition, the results proved that the synthesis method used in this study is effective for the simultaneous doping of heteroatoms. It is considered that various carbon-based anode materials can be designed using this simple technique in the future.

Supplementary Materials: The following are available online at https:/ / www.mdpi.com/article/10 .3390/app112412007/s1: Figure S1: SEM image of SP/C, Figure S2: XRD patterns of undoped carbon material synthesized by same synthesis method using xylene precursor, Figure S3: BET-plot (red) and fitted line (black), Table S1: Related data to BET plot and fitted line.

Author Contributions: Conceptualization, H.-S.Y. and J.K.; methodology, H.-S.Y., S.-W.K. and J.K.; validation, K.-H.K., S.-H.Y., M.-J.H., J.K.; formal analysis, K.-H.K., S.-H.Y., M.-J.H., J.K.; investigation, H.-S.Y., S.-W.K. and J.K.; data curation, H.-S.Y., S.-W.K. and J.K.; writing-original draft preparation, H.-S.Y.; writing-review and editing, K.-H.K., S.-H.Y., M.-J.H., J.K.; supervision, J.K.; project administration, J.K. All authors have read and agreed to the published version of the manuscript.

Funding: This research received no external funding.

Institutional Review Board Statement: Not applicable.

Informed Consent Statement: Not applicable.

Data Availability Statement: Not applicable.

Conflicts of Interest: The authors declare no conflict of interest.

\section{References}

1. Brezesinski, T.; Wang, J.; Tolbert, S.H.; Dunn, B. Ordered Mesoporous A-Moo 3 with Iso-Oriented Nanocrystalline Walls for Thin-Film Pseudocapacitors. Nat. Mater. 2010, 9, 146-151. [CrossRef]

2. Kim, D.-Y.; Kim, H.-V.; Kang, J. In situ synthesis of silicon-carbon composites and application as lithium-ion battery anode materials. Materials 2019, 12, 2871. [CrossRef] [PubMed]

3. Kang, J.; Kim, H.V.; Chae, S.A.; Kim, K.H. A New Strategy for Maximizing the Storage Capacity of Lithium in Carbon Materials. Small 2018, 20, 1704394. [CrossRef]

4. Chao, D.; Zhu, C.; Yang, P.; Xia, X.; Liu, J.; Wang, J.; Fan, X.; Savilov, S.V.; Lin, J.; Fan, H.J.; et al. Array of Nanosheets Render Ultrafast and High-Capacity Na-Ion Storage by Tunable Pseudocapacitance. Nat. Commun. 2016, 7, 12122. [CrossRef] 
5. Chen, M.; Liu, Q.; Hu, Z.; Zhang, Y.; Xing, G.; Tang, Y.; Chou, S.L. Designing Advanced Vanadium-Based Materials to Achieve Electrochemically Active Multielectron Reactions in Sodium/Potassium-Ion Batteries. Adv. Energy Mater. 2020, 10, 2002244. [CrossRef]

6. Chen, W.; Wan, M.; Liu, Q.; Xiong, X.; Yu, F.; Huang, Y. Heteroatom-Doped Carbon Materials: Synthesis, Mechanism, and Application for Sodium-Ion Batteries. Small Methods 2019, 3, 1800323. [CrossRef]

7. Crabtree, G. Perspective: The Energy-Storage Revolution. Nature 2015, 526, S92. [CrossRef] [PubMed]

8. Dunn, B.; Kamath, H.; Tarascon, J.M. Electrical Energy Storage for the Grid: A Battery of Choices. Science 2011, 334, 928-935. [CrossRef]

9. Hwang, J.Y.; Myung, S.T.; Sun, Y.K. Sodium-Ion Batteries: Present and Future. Chem. Soc. Rev. 2017, 46, 3529-3614. [CrossRef] [PubMed]

10. Jana, S.; Thomas, S.; Lee, C.H.; Jun, B.; Lee, S.U. Rational Design of a Pc3 Monolayer: A High-Capacity, Rapidly Charging Anode Material for Sodium-Ion Batteries. Carbon 2020, 157, 420-426. [CrossRef]

11. Jian, Z.; Bommier, C.; Luo, L.; Li, Z.; Wang, W.; Wang, C.; Greaney, P.A.; Ji, X. Insights on the Mechanism of Na-Ion Storage in Soft Carbon Anode. Chem. Mater. 2017, 29, 2314-2320. [CrossRef]

12. Jiang, Y.; Liu, J. Definitions of Pseudocapacitive Materials: A Brief Review. Energy Environ. Mater. 2019, 2, 30-37. [CrossRef]

13. Jing, M.; Chen, Z.; Li, Z.; Li, F.; Chen, M.; Zhou, M.; He, B.; Chen, L.; Hou, Z.; Chen, X. Facile Synthesis of Zns/N, S Co-Doped Carbon Composite from Zinc Metal Complex for High-Performance Sodium-Ion Batteries. ACS Appl. Mater. Interfaces 2018, 10, 704-712. [CrossRef]

14. Kang, J.; Kim, D.Y.; Chae, S.A.; Saito, N.; Choi, S.Y.; Kim, K.H. Maximization of Sodium Storage Capacity of Pure Carbon Material Used in Sodium-Ion Batteries. J. Mater. Chem. A 2019, 7, 16149-16160. [CrossRef]

15. Kim, D.Y.; Kim, D.H.; Kim, S.H.; Lee, E.K.; Park, S.K.; Lee, J.W.; Yun, Y.S.; Choi, S.Y.; Kang, J. Nano Hard Carbon Anodes for Sodium-Ion Batteries. Nanomaterials 2019, 9, 793. [CrossRef] [PubMed]

16. Kim, D.Y.; Li, O.L.; Kang, J. Maximizing the Rate Capability of Carbon-Based Anode Materials for Sodium-Ion Batteries. J. Power Sources 2021, 481, 228973. [CrossRef]

17. Kim, D.Y.; Li, O.L.; Kang, J. Novel Synthesis of Highly Phosphorus-Doped Carbon as an Ultrahigh-Rate Anode for Sodium Ion Batteries. Carbon 2020, 168, 448-457. [CrossRef]

18. Kim, H.; Yun, Y.; Lee, Y.C.; Lee, M.H.; Saito, N.; Kang, J. Synthesis of Silicon-Carbon Black Composite as Anode Material for Lithium Ion Battery. Jpn. J. Appl. Phys. 2017, 57, 0102B2. [CrossRef]

19. Kundu, D.; Talaie, E.; Duffort, V.; Nazar, L.F. The Emerging Chemistry of Sodium Ion Batteries for Electrochemical Energy Storage Angew. Chem. Int. Ed. 2015, 54, 3431-3448. [CrossRef]

20. Manoj, B.; Kunjomana, A.G. Study of stacking structure of amorphous carbon by X-ray diffraction technique. Int. J. Electrochem. Sci. 2012, 7, 3127-3134.

21. Li, W.; Zhou, M.; Li, H.; Wang, K.; Cheng, S.; Jiang, K. A High Performance Sulfur-Doped Disordered Carbon Anode for Sodium Ion Batteries. Energy Environ. Sci. 2015, 8, 2916-2921. [CrossRef]

22. Liu, J. Addressing the Grand Challenges in Energy Storage. Adv. Funct. Mater. 2013, 23, 924-928. [CrossRef]

23. Liu, Y.; Merinov, B.V.; Goddard, W.A. Origin of Low Sodium Capacity in Graphite and Generally Weak Substrate Binding of Na and Mg among Alkali and Alkaline Earth Metals. Proc. Natl. Acad. Sci. USA 2016, 113, 3735-3739. [CrossRef]

24. Moriwake, H.; Kuwabara, A.; Fisher, C.A.; Ikuhara, Y. Why Is Sodium-Intercalated Graphite Unstable? RSC Adv. 2017, 7, 36550-36554. [CrossRef]

25. Slater, M.D.; Kim, D.; Lee, E.; Johnson, C.S. Sodium-Ion Batteries. Adv. Funct. Mater. 2013, 23, 947-958. [CrossRef]

26. Yang, J.; Zhou, X.; Wu, D.; Zhao, X.; Zhou, Z. S-Doped N-Rich Carbon Nanosheets with Expanded Interlayer Distance as Anode Materials for Sodium-Ion Batteries. Adv. Mater. 2017, 29, 1604108. [CrossRef]

27. Ye, J.; Zhao, H.; Song, W.; Wang, N.; Kang, M.; Li, Z. Enhanced Electronic Conductivity and Sodium-Ion Adsorption in N/S Co-Doped Ordered Mesoporous Carbon for High-Performance Sodium-Ion Battery Anode. J. Power Sources 2019, 412, 606-614. [CrossRef]

28. Yu, F.; Liu, Z.; Zhou, R.; Tan, D.; Wang, H.; Wang, F. Pseudocapacitance Contribution in Boron-Doped Graphite Sheets for Anion Storage Enables High-Performance Sodium-Ion Capacitors. Mater. Horiz. 2018, 5, 529-535. [CrossRef] 